\title{
Paracetamol hypersensitivity: a 5 year review
}

\author{
Daniela Malheiro, Maria Sousa*, Ana Moreira, Susana Cadinha, JP Moreira Silva \\ From 6th Drug Hypersensitivity Meeting (DHM 6) \\ Bern, Switzerland. 9-12 April 2014
}

\section{Background}

Paracetamol is a widely used analgesic and antipyretic drug. HS (hypersensitivity reactions) to paracetamol are rare but appear to be increasing. Our aim was to characterize a series of patients with suspected PHS (paracetamol HS).

\section{Methods}

A total of 245 patients with suspected NSAIDs HS were referred to our Drug Allergy Clinic from 2009 to 2013 and those with suspected PHS were evaluated. Demographic data, atopy, comorbidities, HS to other NSAIDs, timing of reaction, clinical manifestations and diagnostic procedures were assessed. PHS was confirmed by a positive DPT (drug provocation test) and considered probable based only on a suggestive clinical history.

\section{Results}

Fifty patients (20.4\%) had suspected PHS: $56 \%$ male, median age 41.5 years [6-81]; $46 \%$ atopic; $18 \%$ had chronic urticaria and/or angioedema, $18 \%$ had asthma and rhinitis and $16 \%$ had rhinitis/rhinoconjunctivitis. Thirty seven patients (74\%) had suspected HS to multiple NSAIDs and $38 \%$ to other drugs, mostly antibiotics. Cutaneous reactions were reported by $60 \%$ of the subjects, both cutaneous and respiratory symptoms by $24 \%$, anaphylaxis by $10 \%$ and isolated respiratory symptoms by $6 \%$. Thirty one (62\%) reported IR (immediate reactions), $32 \%$ DR (delayed reactions) and 6\% were unable to recall the onset of the reaction. SPT and IDT were negative in all patients tested (17 out of 31 with IR; 1 out of 3 with indeterminate reaction); patch tests were negative in 9 out of 16 patients with DR. DPT with Paracetamol was performed in $60 \%$ of the patients and was positive in 4 ( 3 out of 18 with IR; 1 out of 10 with DR). Long term challenge was negative in 10 patients ( 9 with DR and negative DPT; 1 with indeterminate reaction and negative DPT). PHS was confirmed in $4(8 \%)$ patients, excluded in
$32(64 \%)$ and considered probable in $4(8 \%)$. The study was inconclusive in $10(20 \%)$ because patients refused DPT or missed the scheduled appointments. It was possible to confirm HS to other NSAIDs in 1 patient with confirmed $\mathrm{PH}$ and in 3 patients in whom PHS was excluded. HS to other NSAIDs was considered probable in 2 patients with confirmed PHS and in 12 patients with excluded PHS.

\section{Conclusion}

As previously described in the literature, our study suggests that PHS is rare and usually presents with cutaneous symptoms. We observed a predominance of male gender, unlike published reports on NSAIDs HS. Although negative, skin tests did not exclude PHS and DPT remains the gold standard for PHS diagnosis.

Published: 18 July 2014

doi:10.1186/2045-7022-4-S3-P70

Cite this article as: Malheiro et al:: Paracetamol hypersensitivity: a 5 year review. Clinical and Translational Allergy 2014 4(Suppl 3):P70.

Submit your next manuscript to BioMed Central and take full advantage of:

- Convenient online submission

- Thorough peer review

- No space constraints or color figure charges

- Immediate publication on acceptance

- Inclusion in PubMed, CAS, Scopus and Google Scholar

- Research which is freely available for redistribution 